\title{
The outcome of endometrial ablation at Queen Elizabeth the Queen Mother Hospital between 2001-2016
}

\author{
Ahmed El Gohari \\ Queen Elizabeth The Queen Mother Hospital, Kent, United Kingdom \\ Correspondence \\ Queen Elizabeth The Queen Mother Hospital, Kent, United Kingdom, E-mail: ahmedelgohary55@yahoo.com.
}

\begin{abstract}
Objective: to determine the long term risk of hysterectomy following balloon endometrial ablation. Design: retrospective cohort study. Setting: A teaching university NHS hospital(Queen Elizabeth The Queen Mother Hospital. Methods: Patients having balloon endometrial ablation were prospectively recorded in an operating room log-book between 2001 to 2016. This logbook was used to search the pathology laboratory database (Dart and Apex) to identify patients who required a hysterectomy. Results: 796 patients underwent BEA at QEQM Hospital in Margate. The patients' age was between 25 to 60 years. A hysterectomy was subsequently performed in 166 women (20.85\%). The risk of hysterectomy was higher among the 40-50 age group. The shortest time to hysterectomy was 1 year and the longest was 10 years. Conclusion: The risk of having a hysterectomy after endometrial ablation in this study was $8.7 \%$ in the first year after the ablation and this risks drop to $3.5 \%$ in 2 years after the ablation. There was $20.85 \%$ failure rate of endometrial ablation using thermachoice, and this raise the question about the effectiveness of other devices which use ballon ablation like thermablate, cavaterm and librata.
\end{abstract}

Key words: Heavy PV bleeding, endometrial ablation. hysterectomy

\section{Introduction}

Abnormal uterine bleeding is a common presenting symptom it affects about $20 \%$ of childbearing age, approximately $5 \%$ of women aged 30 to 49 years will seek medical care each year ${ }^{1}$.

A detailed history, complete physical and pelvic examinations and appropriate blood tests is required to enable the physician to rule out other causes of bleeding such as pregnancy and any disorders related to it, iatrogenic causes, systemic conditions and genital tract pathology.

Dysfunctional uterine bleeding is diagnosed by exclusion of these other causes ${ }^{2,3}$.

Medical treatment for dysfunctional uterine bleeding may include oral contraceptive pills or 

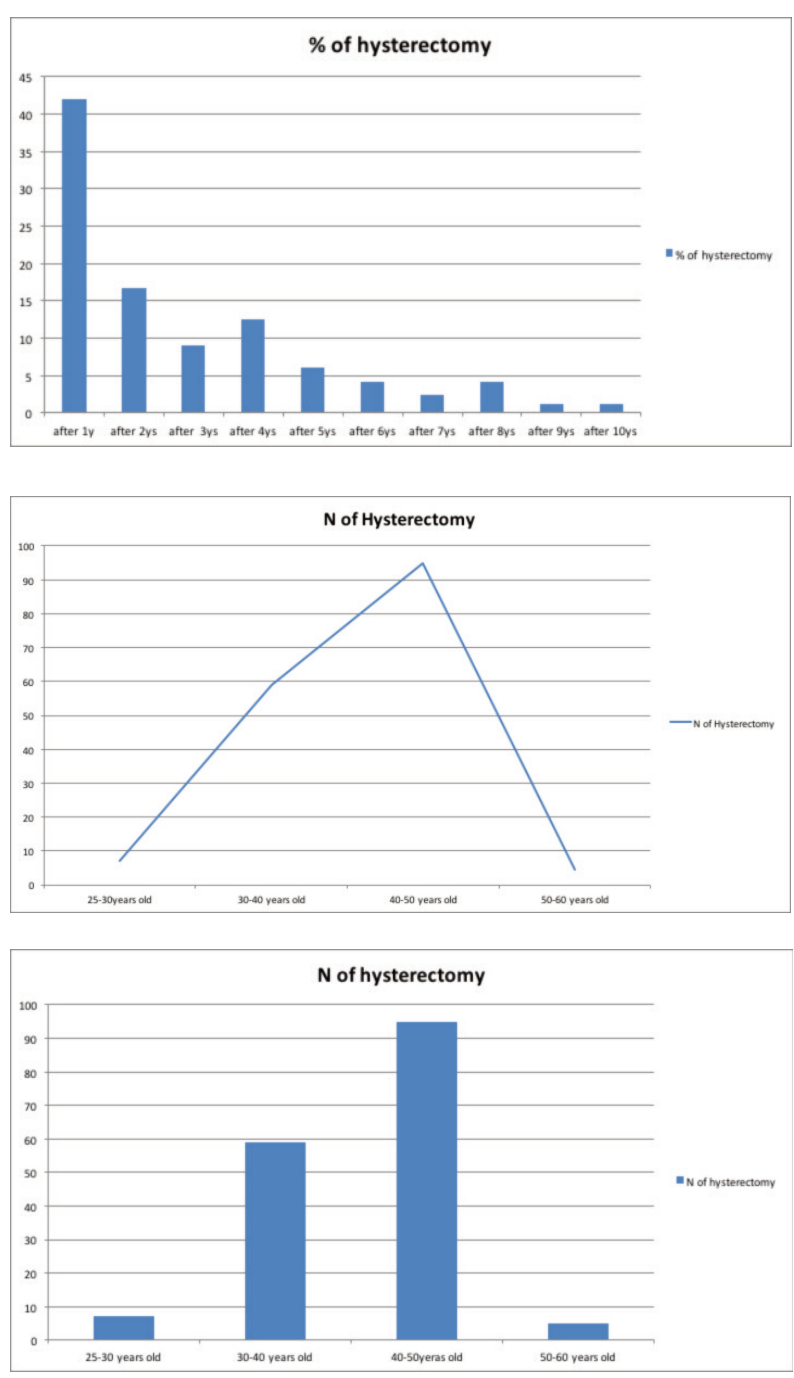

cyclic progestin ${ }^{4,14}$ or non steroidal anti-inflammatory drugs (NSAIDs) or levonorgestrel intrauterine systems (LNGIUS).

When this medical treatment is ineffective or refused by patients, surgical treatment will be the next option especially if fertility is not an issue $\mathrm{e}^{5,14}$.

Initially, hysterectomy was the only choice for patients but in the 1980, targeted Destruction or excision of the endometrium under hysteroscopic guidance was introduced ${ }^{14}$. However, hysteroscopic endometrial ablation requires additional training and a surgical skill.
This led to the introduction of a number of nonhysteroscopic controlled devices, aimed at achieving endometrial destruction. These devices use different energy sources such as hot liquid systems, microwave, bipolar radiofrequency, laser or cryotherapy $^{16}$.

\section{Device description}

Endometrial balloon ablation devices:

1- thermachoice (Gynecare Inc,.somerville NJ),

2- Cavaterm(Wallsten medical, Morgis, Switzerland),

3-Menotreat(lina medical, Glostrup, Denmark) ${ }^{7}$

4-Thermablate(MDMI). ${ }^{8}$

Most studies on a Foley catheter balloon filled with boiling water show an increased success rate in patients over $40.7,10,11,12,13$

The Thermablate system consists of a disposable, prefilled catheter-balloon cartridge and a reusable hand-held treatment control unit (TCU) that runs on direct current and is responsible for heating the liquid in the cartridge.

Hot fluid is pushed through the catheter into the uterine balloon by a pneumatic pump.

Treatment time, pressure, and temperature, as well as safety checks are microprocessor controlled by the TCU.

The cervix is dilated up to 6-7 $\mathrm{mm}$ to allow introduction of the catheter. The temperature is at $173^{\circ} \mathrm{C}$, pressure is at $200 \mathrm{mmHg}$, and treatment time is 128 seconds.

Balloon ablation devices were mainly for women with structurally normal endometrial cavities.

For Thermablate, the range for uterine length should be between 7.5 and $10 \mathrm{~cm}$.

Hysterectomy is the most effective treatment for heavy menstrual bleeding (HMB) but it should not be used as a first line treatment for HMB.

Hysterectomy should be considered only when:

- Other treatment options have failed, are contraindicated or are declined by the woman. 
- There is a wish for amenorrhoea or no longer wishes to retain her fertility. ${ }^{14}$

- The patient requests it and in this case it should be considered after appropriate counselling.

\section{Material and Methods}

A retrospective analysis of all the patients who had endometrial ablation at Queen Elizabeth the Queen mother Hospital (QEQM hospital) in the last 10 years .

The data collected using our local record books at the Day Surgery Unit, as well as our lab records for the histology results.

The aim was to determine how successful endometrial ablation was and what the percentage of the women who needed to undergo hysterectomy after they had endometrial ablation.

We looked at 796 patients who had endometrial ablation between $2001-2016$.

166 patients about $20.85 \%$ had hysterectomy following their endometrial ablation.

The majority of the patients $42.1 \%$ who had hysterectomy were done 1 year after the ablation.

\section{Conclusion}

Endometrial ablation is a safe and effective method for treatment of abnormal uterine bleeding, It is as well considered to be a minimally invasive method for treatment of AUB.

$20.85 \%$ of the patients who had endometrial ablation as treatment of AUB needed to have hysterectomy after the ablation which makes endometrial ablation still a cost effective comparing to hysterectomy as a treatment option for AUB.

The risk of having a hysterectomy after endometrial ablation in this study was $8.7 \%$ in the first year after the ablation and this risk drop to $3.5 \%$ in 2 years after the ablation.

Endometrial ablation can be done as an outpatient procedure; this will need a further study to assess the effectiveness of outpatient endometrial ablation.

\section{References}

1. Gath D, Osborn M, Bungay G, Iles S, Day A., Bond A. et al. Psychiatric disorder and gynaecological symptoms in middle aged women: A community survey. Br Med J 1987; 294: 212.

2. Brenner PF. Differential diagnosis of abnormal uterine bleeding. Am J Obstet Gynecol 1996; 175(2): 766.

3. Livingstone M, Fraser IS. "Mechanisms of abnormal uterine bleeding. Hum Reprod Update 2002;(1):60-7.

4. ACOG Committee on Practice Bulletins, American College of Obstetricians and Gynaecologists. ACOG practice bulletin: management of an ovulatory bleeding. Int J Gynaecol Obstet 2001;72: 263.

5. Bayer SR, DeCherney AH. Clinical manifestations and treatment of dysfunctional uterine bleeding. JAMA 1993;269: 1823.

6. Vilos GA. Global endometrial ablation. J Obstet Gynaecol Can 2000; 22, 668.

7. Ulmsten U, Carstensen H, Faconer $\mathrm{C}$ et al. The safety and efficacy of menotreat, a new ballon device for thermal endometrial ablation. Acta obstet gynecol Scand 2001;80:52-7.

8. Mangeshikar Ps, Kapur A, Yackel DB. Endometrial ablation with a new thermal ballon system.J Am Assoc gynecol laparosc 2003;10:27-32.

9. Singh Kc, Sengupta R, Agarwal N et al. Thermal endometrial ablation. A simple technique. Acta Obstet Gynecol Scand 2001;79:54-9.

10. Baggish MS, Eddie HM. Endometrial ablation: A series of 568 patients treated over an II year period.Am J Obstet Gynecol 1996; 174:908-13.

11. Garry R, Shelley-Jones D, Mooney P, Phillips G. Six hundred endometrial laser ablations. Obstet Gynecol1995;8:24-29.

12. O'Connor H, Mages A Endometrial resection for 
the treatment of menorrhagia. $\mathrm{N}$ Engl J Med 1996;335: 151-6.

13. Martyn P, AIIan B. Lond-term follow up of endometrial ablation. J Am Assoc Gynecol Laparos 1998;5(2): 15-8.

Received 18-1-2018

14. nice.org.uk/guidance/cg44 Heavy menstrual Revised 10-2-2018 bleeding: assessment and management 